\title{
Mapping the potential beverage quality of coffee produced in the Zona da Mata, Minas Gerais, Brazil
}

\author{
Samuel de Assis Silva, ${ }^{a^{*}}$ Daniel Marçal de Queiroz, ${ }^{b}$ Williams Pinto Marques \\ Ferreira, ${ }^{c}$ Paulo Cesar Corrêa ${ }^{b}$ and José Luis dos Santos Rufinod
}

\begin{abstract}
BACKGROUND: Detailed knowledge of coffee production systems enables optimization of crop management, harvesting and post-harvest techniques. In this study, coffee quality is mapped as a function of coffee variety, altitude and terrain aspect attributes. The work was performed in the Zona da Mata, Minas Gerais, Brazil.

RESULTS: A large range of coffee quality grades was observed for the Red Catuai variety. For the Yellow Catuai variety, no quality grades lower than $\mathbf{7 0}$ were observed. Regarding the terrain aspect, samples from the southeast-facing slope (SEFS) and the northwest-facing slope (NWFS) exhibited distinct behaviors. The SEFS samples had a greater range of quality grades than did the NWFS samples. The highest grade was obtained from an NWFS point. The lowest quality values and the largest range of grades were observed at lower altitudes. The extracts from the highest-altitude samples did not produce any low-quality coffee.
\end{abstract}

CONCLUSIONS: The production site's position and altitude are the primary variables that influenced the coffee quality. The study area has micro-regions with grades ranging from 80 to 94 . These areas have the potential for producing specialty coffees.

(c) 2015 Society of Chemical Industry

Keywords: Coffea arabica L.; Catuai; cup quality; aspect; spatial variability

\section{INTRODUCTION}

Most coffee plantations in Brazil grow Coffea arabica L., which provides a product with good quality that is widely sought by the consumer market. The State of Minas Gerais accounts for more than $50 \%$ of the coffee production in Brazil, ${ }^{1}$ approximately $25 \%$ of which is produced in the Zona da Mata region.

In the search for an environmentally and economically sustainable cultivation system, Brazilian coffee production has experienced several modifications. ${ }^{2}$ Adding value through quality improvement has been a focus in recent decades. However, some coffee-growing regions are still unaware of the importance of the quality of the coffee that they produce. ${ }^{3}$

Detailed knowledge of coffee production systems enables optimization of crop management, harvesting and post-harvest techniques. ${ }^{4}$ Spatial variability data of the production system can help to identify areas with the potential for producing better-quality coffees. In addition, these data allow for an understanding of the factors that determine quality and crop yield, helping producers achieve greater profitability. ${ }^{5}$

Factors associated with soil, topography, climate, crop management and variety determine the characteristics of agricultural products. ${ }^{6}$ All of these factors give the product a unique identity that defines the final quality. ${ }^{7}$ To set this identity, it is necessary to characterize the environment, and natural factors need to be considered. . $^{3,8,9}$

For specialty crops, Zou et al. ${ }^{10}$ stated that the location where the crop is grown determines the final quality and defines the subsequent processes that the product needs to be submitted to prior to consumption. According to Rolle et al., ${ }^{11}$ adding information about the geographical origin of an agricultural product facilitates its acceptance in the market.

Coffee is a specialty crop whose diversity in production systems allows products with defined attributes for different markets to be obtained. ${ }^{12}$ To produce a specialty coffee, it is important to take into consideration attributes such as its physical characteristics (e.g. origin, variety, color and size), its beverage quality characteristics (e.g. sweetness, body, acidity and aroma), and environmental and social concerns regarding the production systems. ${ }^{13}$

The key environmental characteristics that affect coffee quality are primarily related to the climate. However, when considering the coffee plantation at more specific levels, other environmental

\footnotetext{
* Correspondence to: Samuel de Assis Silva, Departamento de Engenharia Rural, Universidade Federal do Espírito Santo, Alto Universitário, Cx. Postal 16, Alegre-ES 29500-000, Brazil. E-mail: sasilva@pq.cnpq.br

a Departamento de Engenharia Rural, Universidade Federal do Espírito Santo, Alegre, ES, 29500-000, Brazil

b Departamento de Engenharia Agrícola, Universidade Federal de Viçosa, Viçosa, MG, 36.570-000, Brazil

c Empresa Brasileira de Pesquisa Agropecuária, Viçosa, MG, 36.570-000, Brazil

d Centro de Excelência do Café, Viçosa MG, 36.570-000, Brazil
} 
characteristics, such as the terrain aspect and the altitude where the crop is grown, become relevant. ${ }^{14}$ Altitude defines the microclimate to which a crop is exposed. Generally, higher altitudes have milder climates; thus they tend to produce better-quality coffees. The terrain aspect of the coffee field affects the amount of solar radiation received by the crop. For the Southern Hemisphere, fields with a face slope oriented to the south receive a smaller amount of solar radiation than do those oriented to the north. This lower amount of energy received affects the process of fruit ripening and thus the product quality. However, it still not known how each variable and the interactions among the different variables define coffee quality. Understanding how these variables affect the quality is important for improving the production of specialty coffees.

The mapping of the qualitative potential of coffee is important information for planning and managing the coffee agribusiness. Therefore, the objective of this study was to map the potential quality of coffee produced in the Zona da Mata farms, Minas Gerais State, Brazil. The influences of variety, altitude and terrain aspect on the coffee quality were evaluated.

\section{EXPERIMENTAL}

This study was performed during the $2012 / 2013$ crop season in an eastern region of the State of Minas Gerais known as the Zona da Mata. This area traditionally produces Coffea arabica (Fig. 1). The study area was approximately 1749,114 ha, and it produces an average of 5 million bags of processed coffee per year.

In the region of Zona da Mata, coffee is generally grown in shadeless monoculture. The plantations are cultivated in areas with steep slopes and faces turned in different directions relative to the sun. Plantations are established at different levels of altitude and in different soil types. The plantations are usually made in contour lines, with a spacing of $2.0 \times 1.5 \mathrm{~m}$, and the crops are conducted for many years (over 10 years). Most of the crop management practices are performed manually due to the high slope of the coffee plantation areas.

The beverage coffee quality was determined from 312 sampling points distributed over 14 counties in the region (Fig. 1) in crops of the same age that were cultivated using similar management practices. The points were georeferenced using a GPS device to obtain the geographical coordinates (latitude and longitude), altitude and terrain aspect. The region is described as a mountainous relief with a great variation in altitude (Fig. 2).

In each of the counties analyzed in this study, there was a defined number of sampling points (Table 1). These sampling points took into account the prevalent altitude within the county and the size and importance of the coffee plantation.

The sampling points were equidistantly distributed throughout the study area, with distances between the points being no greater than $1000 \mathrm{~m}$. The objective was to obtain a point distribution that covered the entire coffee production area within a county. The sampling criteria followed the principles introduced by Kerry and Oliver, ${ }^{15}$ who claimed that classical Matheron variogram estimation requires a minimum of 100 sampling points to be reliable and accurate. The sampling points should also be well distributed throughout the study area such that the maximum distance between them is as small as possible. Estimates that are made with greater volumes of data and with smaller distances better represent the phenomenon and lead to subsequent interpretations with greater credibility. ${ }^{16}$

To evaluate the attributes that affect coffee quality, the following parameters were considered at each sampling point: coffee variety, altitude and terrain aspect. The potential qualities of Yellow and Red Catuai coffee varieties were evaluated. These varieties were selected for this study because they are the most commonly planted varieties in the study region.

The quality characteristics of these two varieties were evaluated at four altitude layers relative to sea level and in two different positions relative to the terrain aspect: the southeast-facing slopes (SEFS) and the northwest-facing slopes (NWFS). The altitude layers were defined as follows: less than $700 \mathrm{~m}$, between 700 and $825 \mathrm{~m}$, between 825 and $950 \mathrm{~m}$, and more than $950 \mathrm{~m}$. For each of the two evaluated coffee varieties, coffee samples from four altitude strata and from each terrain aspect were collected and analyzed.

In this study, only fully ripe berries were harvested to prepare the samples for the beverage quality evaluation. This procedure was followed because the goal was to evaluate the potential beverage quality of the coffee of the region. Immature and overripe fruits were not processed to form the sample for quality evaluation because their presence resulted in an inferior coffee quality.

Coffee cherry samples of approximately $1 \mathrm{~kg}$ were collected from each sampling point. During the harvest, approximately 30 plants per hectare were randomly sampled from each plot. Four branches of cherry fruit were collected from each plant by hand: two from each side of the plant. To ensure that the fruits were representative of the plant, these branches were chosen at random. The collected fruits were grouped together, forming a composite sample for each point. After the samples were collected, the fruit was processed by removing the natural skin while preserving the mucilage surrounding the parchment. For this purpose, a manual depulper with a continuous water flow was used. The processed samples were artificially dried using a sample fixed-bed tray drier with a gas burner at an air temperature of $40^{\circ} \mathrm{C}\left( \pm 1^{\circ} \mathrm{C}\right)$ to a water content of approximately $12 \%$ wet basis. The fruit water content was monitored using a Gehaka model G800 (Gehaka Industry and Commerce, São Paulo, Brazil) digital moisture meter for cereals. The dried samples were processed using a model DRC-1 No. 830 portable sample peeler. Samples were then placed in plastic containers and stored in a BOD (biochemical oxygen demand)-type incubator for a period of approximately 2 months before the physical and sensory quality tests were performed.

The quality of the coffee was assessed using a beverage quality analysis process popularly known as the cup test, according to the protocol of the Brazilian Specialty Coffee Association (BSCA). For each sample, the following sensorial attributes were evaluated: drink, sweetness, acidity, body, flavor, aftertaste, balance and general perception (based on joint perception of quality attributes evaluated), with grades ranging from 0 to 8 . By combining these scores, the overall grade for each sample was determined. According to the protocol, each sample begins with a pre-set score of 36 points, to which will be added the scores of each attribute. Those samples that presented scores over 80 were classified as specialty coffee.

For the beverage quality evaluation, the samples were roasted $24 \mathrm{~h}$ before the quality evaluation. The roasting was controlled to occur over a period of 8-12 min. After roasting, the samples were rested for at least $8 \mathrm{~h}$ before performing the beverage quality analysis. The roasting degree was measured using MBasic Agtron (Agtron Inc., Reno, NV, USA) equipment.

After the rest period of the roasted samples, they were ground immediately before tasting, obtaining $70 \%$ and $75 \%$ particles with the equivalent diameter of 20 mesh sieve holes (US standard). For each new sample, the grinder was submitted to a purification 



Figure 1. Coverage of the county and state regions used to collect data for the mapping of coffee quality potential. 

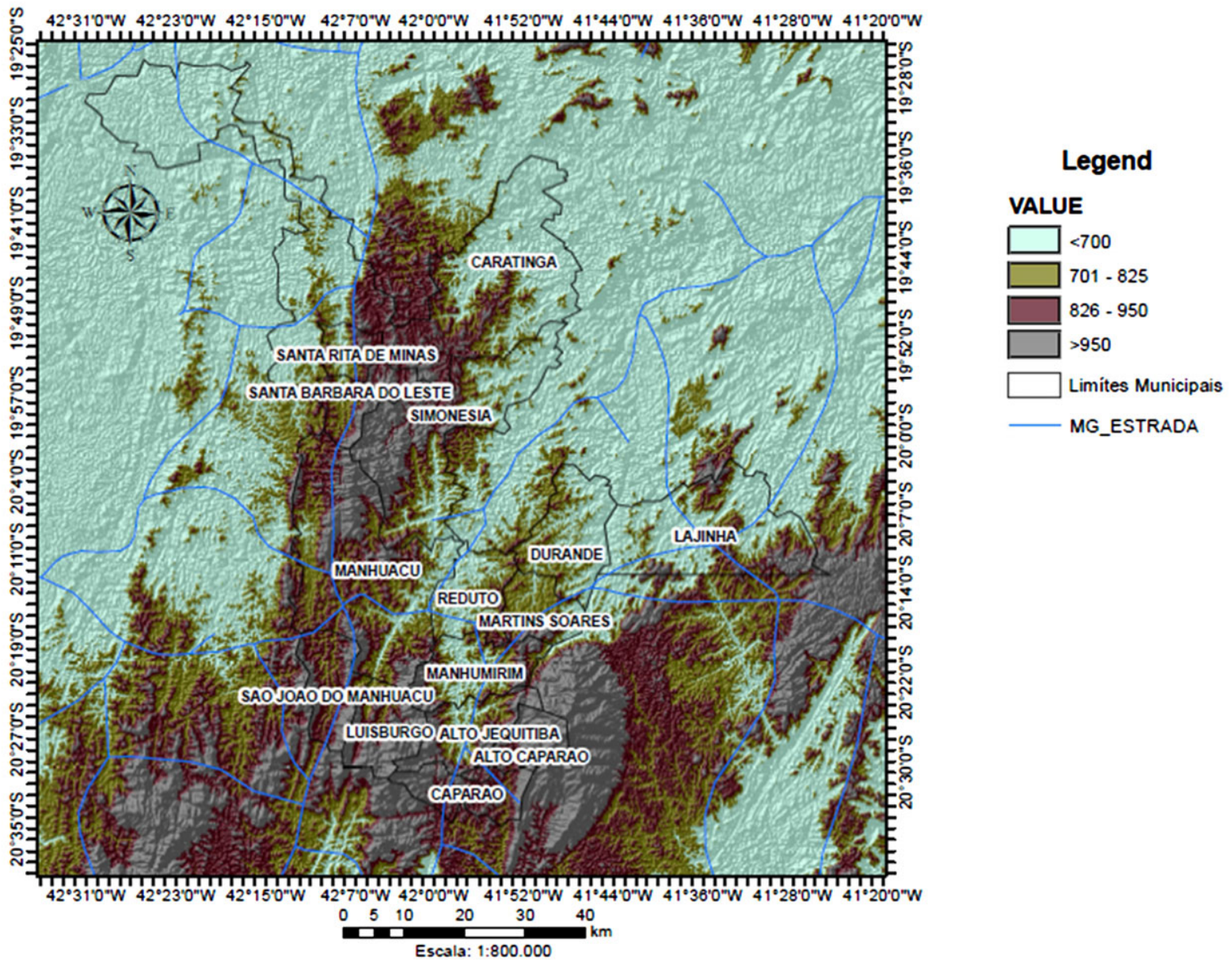

Figure 2. Altitude of the region covered by the study of coffee quality. The counties and sites of data collection are highlighted.

\begin{tabular}{|lc|}
\hline $\begin{array}{l}\text { Table 1. Distribution of sampling points in the counties involved in } \\
\text { the project }\end{array}$ \\
\hline County & Number of samples \\
\hline Manhumirim & 20 \\
Caratinga & 20 \\
Santa Rita de Minas & 20 \\
Santa Bárbara do Leste & 20 \\
Simonésia & 20 \\
Manhuaçu & 48 \\
Reduto & 20 \\
Martins Soares & 20 \\
São João do Manhuaçu & 20 \\
Durandé & 20 \\
Luisburgo & 20 \\
Alto Jequitibá & 20 \\
Alto Caparaó & 20 \\
Lajinha & 24 \\
Total & 312 \\
\hline
\end{tabular}

process, which consists of grinding a small volume prior to the next sample to prevent contamination with residues of the previous sample.
For the composition to be tasted and evaluated for effusion, a ratio of $8.5 \mathrm{~g}$ ground coffee per $150 \mathrm{~mL}$ hot water was used. Special care was given to the water used for tasting to ensure that it was clean and odorless and that it had a suitable $\mathrm{pH}$. The water was heated to approximately $93^{\circ} \mathrm{C}$ and was subsequently added to the ground coffee. Water was added directly to the ground coffee in a circular motion, filling the cup until it was completely full. After this hydration process, the samples remained undisturbed for 3-5 min prior to proceeding to the review.

The main characteristic of the methodology was to objectively evaluate the beverage quality and not to analyze its shortcomings, scoring the coffee samples on a scale from 0 to 100 points. The BSCA ${ }^{17}$ protocol was used: $90-100$ points $=$ special coffee; 85-89.99 (below 90) = excellent coffee; 80-84.99 (below 85 ) $=$ fine coffee; and below $80=$ coffee of less than premium quality, which was not classified. According to this classification, a specialty coffee cannot be defective; it must also have at least one well-defined attribute, such as aroma, flavor, body or acidity.

According to BSCA methodology, coffees that have grades below 80 are not classified. This designation means that a coffee that does not possess features that reflect a unique and particular flavor or has a quality that is defective will be removed from classification. The beverage quality analysis was performed by three tasters, controlled and professionally trained by the CQI (Coffee Quality Institute), known as Q-graders; each taster made only one determination per sample. From each coffee sample, 
five cups were prepared and analyzed according to the sensory characteristics described above.

A geographical map of the 'Café das Matas de Minas' Project Coverage Region (Fig. 2) was prepared with the latitude and longitude coordinates encircled in the areas of interest for characterization of the region. This map was created using the ArcMap application from ARCGIS version 10.0 software (Esri, Redlands, CA, USA). Files in shapefile format from the IBGE cartographic database were used.

To determine the behavior of the central tendency and dispersion quality, the data were initially submitted to a descriptive statistical analysis to define the distribution of univariate data. Scatter plots were constructed (box-plot) to evaluate the behavior of the data in relation to a central value (median). These results were expressed in terms of both the individual quality characteristics and the overall drink quality.

The data were analyzed based on the measuring location (means and medians), dispersion (maximum and minimum values, standard deviations, variances and coefficients of variation) and the dispersion form (coefficients of asymmetry and kurtosis). Normality was tested using the Shapiro-Wilk test $(P<0.05)$.

To evaluate the joint influence of the variation sources (i.e. altitude, variety and terrain aspect) on drink quality, the data were subjected to separation Tukey tests at a $5 \%$ probability level. For this purpose, an experimental arrangement in a $4 \times 2 \times 2$ factorial scheme was considered (4 altitudes, 2 varieties and 2 terrain aspects). Classical statistical analysis was performed using Statistica software, version 7.0.

Geostatistics were used to quantify the degree of spatial dependence from the adjustment of theoretical functions to the experimental variogram models for all of the samples (312 points); NWFS (156 points); SEFS (156 points); Red Catuai variety (156 points); and Yellow Catuai variety (156 points). The analysis was based on the assumption of the stationary intrinsic hypothesis and according to Eqn (1): $:^{18}$

$$
\gamma(h)=\frac{1}{2 N(h)} \sum_{i=1}^{N(h)}\left[z\left(x_{i}\right)-z\left(x_{i}+h\right)\right]^{2}
$$

where $N(h)$ is the number of pairs of values $\left[Z\left(x_{i}\right), Z\left(x_{i}+h\right)\right]$ separated by an $h$ vector and $x_{i}$ is a spatial position of the $Z$ variable. The point cloud $[h, \gamma(h)]$ is adjusted to a mathematical function whose parameters are known as follows: a nugget effect $\left(C_{0}\right)$, corresponding to the intersection value from the axis of the semivariances; the position $\left(C_{0}+C\right)$, approximately equal to the variance value of the data; and the reach $(a)$, which represents the distance at which the variogram reaches the position value.

After the identification of spatial dependence, the interpolation method of ordinary kriging was used to estimate values at unmeasured locations.

\section{RESULTS AND DISCUSSION}

The dispersion analysis of overall drink quality is shown in Fig. 3. Upon examining the overall coffee quality figures, a large range of quality distribution was observed. All data were normally distributed, according to the Shapiro-Wilk test $(P<0.05)$. When all of the results were considered (312 samples), samples with grades below 70 points and grades higher than 90 points were included. According to the BSCA criteria, most of the coffee samples collected from the Serras de Minas region of Minas Gerais during the 2012/2013 harvest were classified as excellent coffee from a special source. Silva et al. ${ }^{3}$ reported similar results when characterizing coffee terroirs from plantations in Minas Gerais in the 2011/2012 harvest. These results indicate that, under favorable environmental conditions, the special coffee production potential in the region is high.

The quality scores ranged from 68 to 94 , with $50 \%$ of the grades concentrated between 80 and 84 points; only a few extreme values were below 70 points. Luz ${ }^{19}$ evaluated the effects of climate on the coffee quality for Minas Gerais state, Brazil, over four consecutive crop seasons (2008/2009-2010/2011 crop seasons) and observed that $50 \%$ of the quality grades were in the range of 75-80 points; likewise, a few samples presented grades below 70 points. This author noted that the grade distribution had the same behavior for each of the four crop seasons, similar to what was observed by DaMatta and Ramalho. ${ }^{20}$ These authors concluded that the pattern of coffee quality tends to remain constant over the years, even with small climate variations. For these authors, only non-typical weather conditions were able to significantly influence the beverage quality of coffee, but weather year to year does not define the quality potential of a production field. The results observed by Luz ${ }^{19}$ and DaMatta and Ramalho ${ }^{20}$ indicate that under normal weather conditions there is no change in the pattern of coffee quality variability. This fact, coupled with a high sample density, indicates that the use of a single crop is efficient to define the quality potential of an area.

A large range of coffee quality grades was observed for the Red Catuai variety. A high dispersion in quality values indicates great variability in pattern-produced coffee. In this situation, the definition of a common standard for the entire region is complicated because there may be more than one terroir. For the Yellow Catuai variety, despite the large range in the results, no quality points lower than 70 were observed. Therefore, no coffees with qualities that were equal to the standard of hard drinking coffee were observed for this variety under the study conditions.

Regarding the terrain aspect, samples from SEFS and NWFS had distinct behaviors, regardless of the variety and altitude (Fig. 3a). The quality grades of samples from the SEFS terrain aspect had greater ranges than did samples from the NWFS. For the SEFS, samples with grades lower than 70 were observed. For the NWFS, no samples had a grade below 74 , and the sample that obtained the highest grade among the 312 coffee samples analyzed originated from this terrain aspect.

When the overall quality results were analyzed based on altitude (Fig. 3b), an important piece of evidence emerged. Both the highest and lowest individual grades were found at the lowest altitudes $(<700 \mathrm{~m})$. This result partially contradicted the literature, as the highest-quality grades are generally found at higher altitudes; several authors have previously discussed this phenomenon. ${ }^{3,21,22}$ One explanation for this result can be found by considering the soil and the characteristics of the locations where these high values were observed. ${ }^{23}$

Despite the contradictory results discussed above, the lowest quality values and the greatest distribution amplitude were observed at lower altitudes. These results indicate that, despite the fact that the grades of some fields were high, the mean quality grade of the coffee from this range of altitude was lower than the grades at higher altitudes. The higher-altitude samples, despite not having the highest overall quality values, did not produce any low-quality coffees; this result confirms the observed values reported in the literature.

By comparing the quality of the two varieties, it was observed that the quality distribution was more uniform in the Yellow Catuai variety, ranging from 74 to 91 . The Yellow Catuai presented a 



Figure 3. Frequency distribution for (a) overall coffee quality (All) and for values stratified by terrain aspect and by variety. (b) Frequency distribution for overall coffee quality stratified by crop altitude. NWFS, northwest-facing slopes; SEFS, southeast-facing slopes.

higher percentage of coffee samples considered to be specialty coffee than the Red Catuai variety. The highest quality grade was observed for coffee variety Catuai Vermelho (grade 94); however, this variety also presented the lowest grade (below 70). Silva et al. ${ }^{24}$ evaluated the quality of six varieties of Arabica coffee grown in Minas Gerais State, Brazil and obtained the highest scores for the Red Catuai variety. These authors did not find coffees in the Yellow Catuai variety with grades greater than 80 . The apparent contradiction of these results to what was found in the present work may be associated with characteristics of the regions where the two works were conducted. Silva et al. ${ }^{24}$ developed their work in the Brazilian Cerrado region, which presents a different environment compared to the mountain fields where the present work was conducted.

When the mean overall quality was comparatively analyzed (Table 2 ) considering a factorial experiment scheme $(4 \times 2 \times 2$, with 31 repetitions), it was observed that only altitude influenced coffee quality. The individual effects caused by the terrain aspect and variety were not statistically significant.

When analyzing the interactions between the factors, the combinations of altitude $\times$ side, altitude $\times$ variety and side $\times$ variety statistically influenced the overall quality values, as noted in Table 2. Despite the significant interactions between these variation sources, the three together did not influence drink quality. 
Table 2. Variance analysis of coffee quality in a factorial scheme with three factors (altitude, F1; terrain aspect, F2; cultivated varieties, F3)

\begin{tabular}{lcccc} 
FV & d.f. & SS & MS & $F$ \\
\hline Altitude $(F 1)$ & 3 & 159.45122 & 53.15041 & $7.9155^{*}$ \\
Terrain aspect $(F 2)$ & 1 & 0.3751 & 0.3751 & 0.0559 n.s. \\
Variety $(F 3)$ & 1 & 0.65613 & 0.65613 & 0.0977 n.s. \\
Interaction $F 1 \times F 2$ & 3 & 67.1448 & 22.3816 & $3.3332^{*}$ \\
Interaction $F 1 \times F 3$ & 3 & 78.01779 & 26.00593 & $3.8730^{*}$ \\
Interaction $F 2 \times F 3$ & 1 & 109.11566 & 109.11566 & $16.2502^{*}$ \\
Interaction $F 1 \times F 2 \times F 3$ & 3 & 39.3722 & 13.12407 & 1.9545 n.s. \\
Statistical treatments & 15 & 454.1329 & 30.27553 & $4.5088^{*}$ \\
Residual & 480 & 3223.06219 & 6.71471 & \\
Total & 495 & 3677.1951 & & \\
\hline
\end{tabular}

FV, Source of variation; d.f., degrees of freedom; SS, sum of square; MS, mean of square. *Significant at a $5 \%$ level of probability $(0.01 \leq P$ $<0.05)$; n.s., not significant $(P \geq 0.05)$.

That is, a joint effect was not observed, and these variables did not express a differentiable qualitative standard. As previously discussed, it is possible to verify that the grade dispersion is less for extracts from the highest altitude, despite the smaller mean value, as is found when more detailed analyses that consider data distribution and not just the mean value are used.

Other sources of variation were determined to be insignificant by the $F$-test during variance analysis. No separation testing was applied because the aforementioned $F$-test was conclusive in verifying that there was no contrast among the statistically nonzero means.

Considering the interaction between altitude and the terrain aspect (Table 3), no statistically significant differences were found for SEFS extracts grown at different altitudes. This result indicates that the quality behavior, based on the mean values, was equal. On the NWFS, the quality of the extract from the 825 to $950 \mathrm{~m}$ altitude was inferior to the other extracts. Given this finding, it is possible that quality behavior on the SEFS is independent of altitude; when coffee is grown with this terrain orientation, similar values can always be expected. Silva ${ }^{25}$ did not observe any influence from the terrain slope on the overall drink quality for different varieties of Arabica from plantations in Araponga, Minas Gerais. In the vine cultivation, Somkuwar et al. ${ }^{26}$ found that factors such as orientation of the crop row to the sun and the altitude of the vineyard significantly influenced grape uniformity, quality and production.

Quality was analyzed at different altitudes and compared based on the terrain aspect. With the exception of the extract from 82-950 $\mathrm{m}$ altitude, where quality was greater in the sample from the SEFS compared to the sample from the NWFS, there were no statistically significant differences in quality grades.

The interaction between altitude and cultivated variety was also analyzed (Table 4). The Yellow Catuai variety behaved similarly at the two extremes in altitude; a difference in quality was observed in the extract from the intermediate altitudes. The Red Catuai variety behaved similarly in the extracts from all altitudes; no significant differences were observed between the mean overall quality grades.

Quality was analyzed at different altitudes and compared based on the cultivated variety. In extracts from the lowest altitude $(<700 \mathrm{~m})$, the yellow variety had a mean quality that was greater than that of the red variety. Otherwise, no statistically significant differences were observed in the quality grades between the varieties. Silva et al. ${ }^{3}$ assessed the quality of coffee produced in the south of Minas Gerais and observed that coffee grown between 920 to $1100 \mathrm{~m}$ was of better quality than coffee grown at 720 to $920 \mathrm{~m}$; these results differ from those observed in this study.

Given the above findings, the Yellow Catuai variety appears to be better suited to lower altitudes than the Red Catuai variety. At medium and higher altitudes, there do not appear to be restrictions in terms of the variety to be cultivated.

The interaction between terrain aspect and variety cultivated is presented in Table 5. The Yellow Catuai variety had better overall quality results on the SEFS. The Red Catuai variety had better results on the NWFS. These results are very important from an implantation planning and coffee plantation renovation perspective. Coffee producers in the region should be encouraged to explore the potential of different available varieties based on the natural characteristics of their production areas.

After statistical analysis, the data were submitted to geostatistics to define and quantify the spatial dependency indexes of the overall coffee quality at all 312 sampling points. The cultivated variety and the terrain aspect were also evaluated. All variables showed spatial dependence; the variogram results are shown in Table 6.

The analysis of the 312 points and of the Red Catuai variety was set to the spherical model; all other variables were set to the exponential model. The determination coefficients for the models ranged from $79.10 \%$ to $89.30 \%$, with a majority of values above $80 \%$.

The smallest range was observed for the 312 assessed points. The other variables had the same spatial pattern, with very close range values. Kerry and Oliver ${ }^{15}$ stated that the spatial dependency range value indicated, up to the radius limit, that the samples showed a correlation between themselves. Points located after the semivariance range were random in behavior, and the mathematical expectation was equal to the mean.

Based on the semivariance models and parameters, the data were interpolated using the ordinary kriging method. Thematic maps were constructed to show the coffee quality produced at all 312 sampling points (Fig. 4), coffee quality values obtained from points located on the SEFS (Fig. 5) and the NWFS (Fig. 6), and coffee quality values for the Yellow Catuai (Fig. 7) and Red Catuai coffee varieties (Fig. 8).

For quality assessments at all sampling points, the highest grades were observed in Simonésia, Lajinha, the western region of Manhuaçú, Manhumirim, Alto Caparaó, Alto Jequitibá and Caparaó. Of these, Manhumirim, Alto Caparaó, Alto Jequitibá and Caparaó had the highest altitudes out of the areas evaluated, as is noted in Fig. 2. In Simonésia and Lajinha, higher quality values did not correlate with higher altitude, as these areas are below $700 \mathrm{~m}$. As discussed previously, these results can be associated with the greater nutritional balance that is observed in coffee cultivated in organic soils. ${ }^{4}$ According to Zou et al. ${ }^{10}$ the physical, organic and geochemical variations of soil permit discrimination of grapes and wine in the different locations.

The lowest overall coffee quality grades were observed in the eastern region of Manhuaçú county and in the far north region of Caratinga county. Lower quality is to be expected in Caratinga county given that it had the highest average temperatures among the regions involved in the study, with higher peaks at all phenological coffee phases. Avelino et al. ${ }^{21}$ noted that climate is a potential factor that can change the qualitative standard of coffee. Very high temperatures can lead to poor bud formation, followed 
Table 3. Separation test for drink quality considering the interaction between altitude and terrain aspect

\begin{tabular}{llcccc} 
& \multicolumn{3}{c}{ Southeast-facing slopes } & \multicolumn{2}{c}{ Northwest-facing slopes } \\
\cline { 2 - 4 } Altitude & $n$ & Means of quality & SD & $n$ & Means of quality \\
\hline$<700$ & 39 & $83.2 \mathrm{aA}$ & 4.7 & 39 & $83.3 \mathrm{aA}$ \\
$700-825$ & 39 & $82.6 \mathrm{aA}$ & 3.5 & 39 & $82.8 \mathrm{aA}$ \\
$825-950$ & 39 & $82.2 \mathrm{aA}$ & 3.1 & 39 & $81.2 \mathrm{bB}$ \\
$>950$ & 39 & $82.3 \mathrm{aB}$ & 3.1 & 39 & 3.6 \\
\hline
\end{tabular}

Least significant difference for columns $=1.1975$; least significant difference for rows $=0.9130 ; n=$ number of samples; $S D=$ standard deviation. Means in a column followed by the same letter and in a row with the same upper-case letter are not significantly different according to the Tukey test at a $5 \%$ probability level $(P<0.05)$.

Table 4. Separation test for drink quality considering the interaction between altitude and variety

\begin{tabular}{|c|c|c|c|c|c|c|}
\hline \multirow[b]{2}{*}{ Altitude } & \multicolumn{3}{|c|}{ Yellow } & \multicolumn{3}{|c|}{ Red } \\
\hline & $n$ & Means of quality & SD & $n$ & Means of quality & SD \\
\hline$<700$ & 39 & 83.7aA & 4.0 & 39 & $82.8 \mathrm{aB}$ & 4.9 \\
\hline $700-825$ & 39 & $82.2 \mathrm{bcA}$ & 2.8 & 39 & $83.2 \mathrm{aA}$ & 3.9 \\
\hline $825-950$ & 39 & $81.5 \mathrm{cA}$ & 3.6 & 39 & $82.0 \mathrm{aA}$ & 2.6 \\
\hline$>950$ & 39 & 83.2abA & 3.6 & 39 & $82.4 \mathrm{aA}$ & 2.0 \\
\hline
\end{tabular}

Least significant difference for columns $=1.1975$; least significant difference for rows $=0.9130 ; n=$ number of samples; SD $=$ standard deviation. Means in a column followed by the same letter and in a row with the same upper-case letter are not significantly different according to the Tukey test at a $5 \%$ probability level $(P<0.05)$.

Table 5. Separation test for drink quality considering the interaction between variety and terrain aspect

\begin{tabular}{|c|c|c|c|c|c|c|}
\hline \multirow[b]{2}{*}{ Terrain aspect } & \multicolumn{3}{|c|}{ Yellow } & \multicolumn{3}{|c|}{ Red } \\
\hline & $n$ & Means of quality & SD & $n$ & Means of quality & SD \\
\hline Southeast-facing slopes & 78 & $83,1 \mathrm{aA}$ & 3.5 & 78 & $82,1 \mathrm{bB}$ & 4.1 \\
\hline Northwest-facing slopes & 78 & $82,2 \mathrm{bB}$ & 3.2 & 78 & $83,1 \mathrm{aA}$ & 2.7 \\
\hline
\end{tabular}

Table 6. Models and parameters for the estimated mean variograms for all overall coffee quality results (All), for the stratified values in the terrain aspect, and for the two varieties (Red and Yellow Catuai)

\begin{tabular}{|c|c|c|c|c|c|c|c|c|}
\hline \multirow[b]{2}{*}{ Variable } & \multicolumn{8}{|c|}{ Models and parameters } \\
\hline & Model & $C_{0}$ & $C_{0}+C$ & $a$ & RSS & IDE & $R^{2}$ & $R^{2}(\mathrm{VC})$ \\
\hline All & Spherical & 0.44 & 0.72 & 3683 & 2.55 & 40.00 & 84.00 & 28.80 \\
\hline Northwest-facing slopes & Exponential & 0.41 & 0.85 & 5208 & 1.91 & 52.20 & 79.10 & 26.40 \\
\hline Southeast-facing slopes & Exponential & 0.29 & 0.79 & 5532 & 3.16 & 63.70 & 80.40 & 32.10 \\
\hline Red Catuai & Spherical & 0.35 & 0.95 & 5470 & 2.92 & 63.70 & 89.30 & 37.50 \\
\hline Yellow Catuai & Exponential & 0.29 & 0.87 & 5686 & 3.71 & 66.60 & 85.00 & 36.80 \\
\hline
\end{tabular}




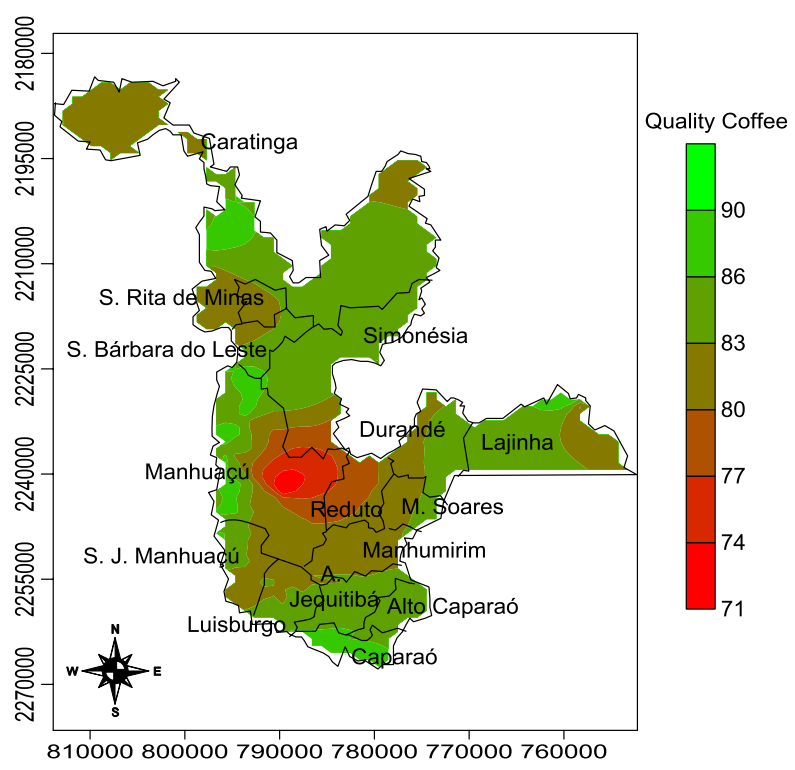

Figure 4. Contour map of the estimated quality grades from all 312 sampling points.

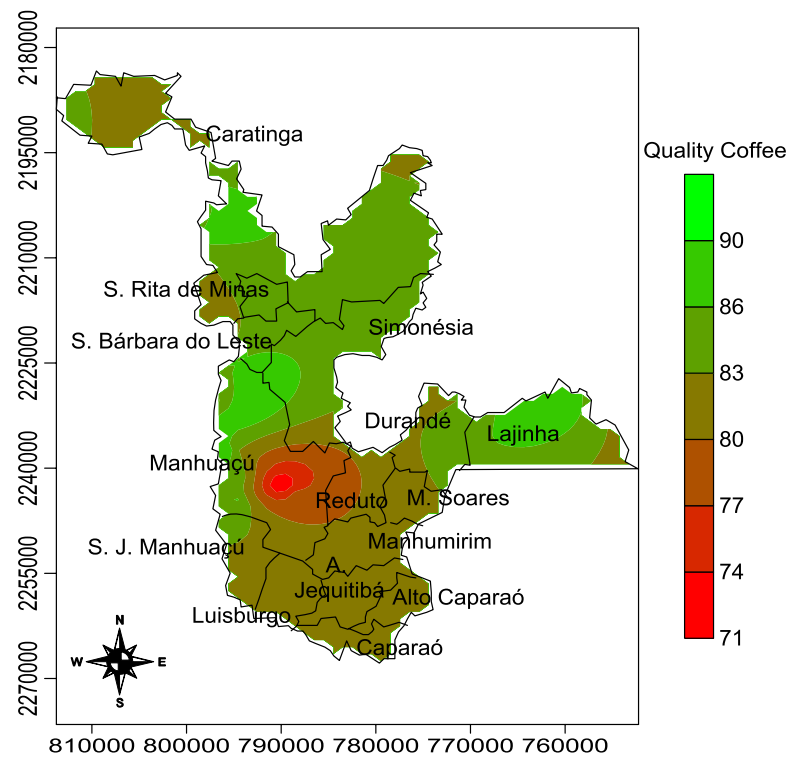

Figure 5. Contour map of the estimated quality grades on the southeast-facing slopes.

by poor flowering with low-quality flowers; ${ }^{27}$ according to Silva, ${ }^{25}$ such development tends to impair the end quality of the coffee.

When the quality of coffee grown only on the SEFS is considered (Fig. 5), greater spatial continuity was observed. Quality grades remained higher in Lajinha, Simonésia and the western region of Manhuaçú. However, the quality grades observed in Manhumirim, Alto Caparaó, Alto Jequitibá and Caparaó did not follow the same behavior. In these counties, the quality denominations remained high but were lower than those observed in Fig. 4 when all samples were considered. The eastern region of Manhuaçú had the lowest quality grades, as previously observed.

The quality observed on the NWFS (Fig. 6) differed greatly from values observed on the SEFS. The counties of Manhumirim, Alto Caparaó, Alto Jequitibá and Caparaó had the highest grades; Simonésia and Lajinha had considerably lower grades on the

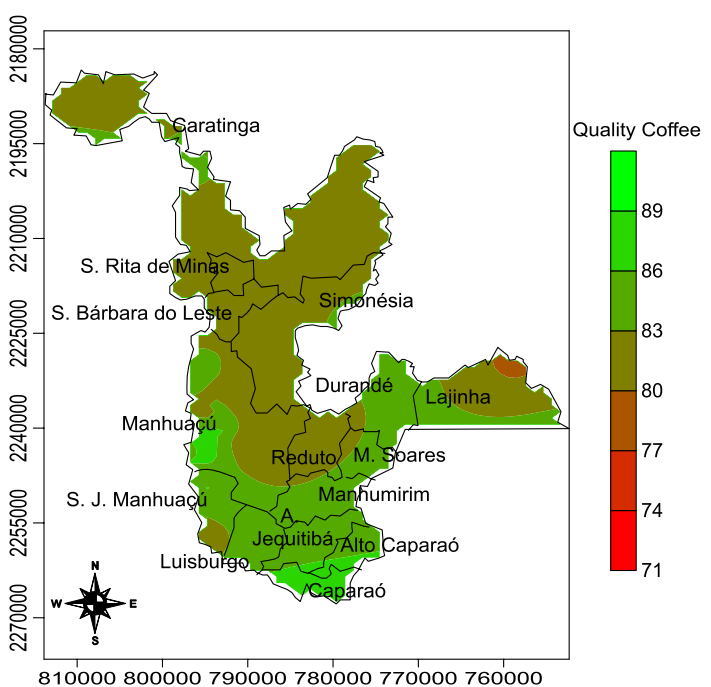

Figure 6. Contour map of estimated quality grades on the northwest-facing slopes.

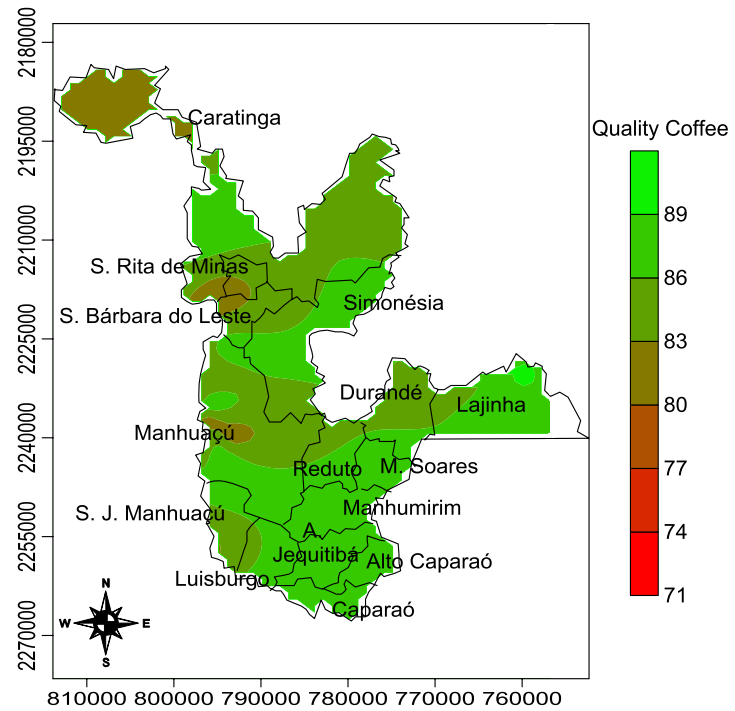

Figure 7. Contour map of estimated quality grades for the Yellow Catuai variety.

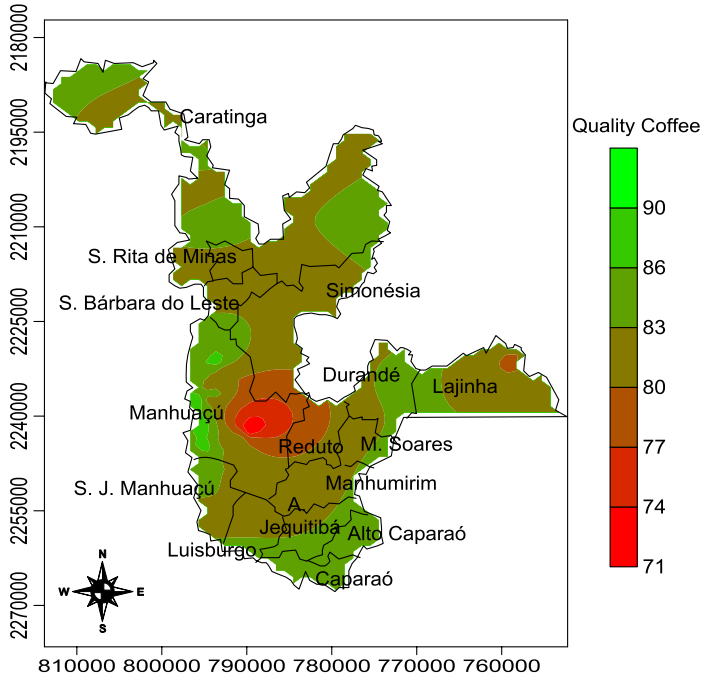

Figure 8. Contour map of estimated quality grades for the Red Catuai variety. 
NWFS. These results indicate that quality is greater in Manhumirim, Alto Caparaó, Alto Jequitibá and Caparaó when coffee is grown on the NWFS; in Simonésia and Lajinha, quality is greater in samples grown on the SEFS. The western region of Manhuaçú had high quality grades when samples were grown on the NWFS, indicating that this region has great potential for the production of specialty coffee regardless of this geographical feature. Silva et al. ${ }^{3}$ claimed that defining areas that have very specific quality characteristics is an important step towards coffee differentiation and is therefore essential for defining terroirs.

An important piece of information can be extracted from the maps in Figs 5 and 6; quality is a function of altitude in the Zona da Mata's counties. On the NWFS, counties with lower altitudes tended to produce lower-quality coffee than that found in counties with higher altitudes. However, such behavior was not as evident on the SEFS. The amplitude of the variation in quality between these counties was lower. These results demonstrate that the altitude effect is softened for the SEFS. DaMatta ${ }^{28}$ commented that the terrain aspect appears to regulate the yield of plants and consequently alters the qualitative characteristics of the fruit.

When analyzing quality based on variety (Figs 7 and 8), it was observed that the Yellow Catuai variety produces superior quality coffee compared to the Red Catuai variety. This difference is because the variation of spatial distribution is lower for the Yellow Catuai variety. Only grades higher than 80 points, with most grades above 86, were observed, particularly in the counties of Caparaó, Alto Caparaó and Lajinha.

For the Red Catuai variety, grades below 70 (in the eastern region of Manhuaçú) and a predominance of grades between 80 and 86 were observed. In the western region of Manhuaçú, this variety stood out in terms of specialty coffee production; the same was not observed for the Yellow Catuai variety. Another county where this variety stood out was Caratinga, where quality grades were greater than 83.

In terms of the overall quality, a correlation was not observed between the variety and the altitude of the county where the coffee was grown for the Red Catuai variety. This finding corroborated the results observed during separation tests, where no significant differences between the different altitude layers were observed. Silva ${ }^{25}$ also did not observe a varietal effect based on the altitude of the plantations on the quality of coffee in counties from the Sierras de Minas region. According to this author, factors such as the microclimate are most meaningful when defining the coffee quality and, in many instances, inhibit the effects of other variables.

The factors that most affected coffee quality were the altitude and the terrain aspect of the plantations, particularly when considering the spatial distribution of quality in relation to these characteristics. Several authors have commented on the positive effect of altitude on overall coffee quality. ${ }^{22,25,29-31}$ However, the results obtained in these studies showed that the joint action of altitude and the position of the plantation have an influence on overall coffee quality. Zsófi et al. ${ }^{32}$ stated that, among the many factors that determine grape quality, altitude and position of the grapevine have the greatest influence. Carey et al. ${ }^{33}$ stated that this influence occurs because these variables had greater continuity when compared to others with greater variability, which results in a more homogeneous influence along the landscape.

\section{CONCLUSIONS}

Altitude is important for obtaining specialty coffees, but altitude alone is not the only factor that defines the product quality.

The Yellow Catuai variety does not produce coffees with grades lower than 70 points; instead, it produces coffees with qualities greater than or equal to the standard of hard drinking coffee.

The northwestern-facing slopes, fields with lower altitudes and warmer climates produce poorer-quality coffees than fields with higher altitudes and mild temperatures.

The position and altitude of the fields are the main variables that influence coffee quality. This quality depends on where the field is located and, in turn, on the altitude and the position of the plantation.

The study area has potential for producing specialty and differentiable coffee, and the production of coffee with different terroirs should be promoted.

\section{ACKNOWLEDGEMENTS}

The authors wish to acknowledge the Serviço Brasileiro de Apoio às Micro e Pequenas Empresas - SEBRAE/MG (Brazilian Support Service for Micro and Small Businesses) for their financial support in performing this study.

\section{REFERENCES}

1 CONAB (Companhia Nacional de Abastecimento), Acompanhamento da Safra Brasileira - Café. CONAB, Brasília (2013).

2 Petek MR, Sera T, Sera GH, Fonseca ICB and Ito DS, Seleção de progênies de Coffea arabica com resistência simultânea à mancha aureolada e à ferrugem alaranjada. Bragantia 65:65-73 (2006).

3 Silva SA, Queiroz DM, Pinto FAC and Santos NT, Characterization and delimitation of coffee terroirs in plantations in the municipal district of Araponga, Minas Gerais. Rev Ciênc Agron 45:18-26 (2014).

4 Silva SA, Lima JSS and Bottega EL, Yield mapping of arabic coffee and their relationship with plant nutritional status. J Soil Sci Plant Nutr 4:34-42 (2013).

5 Silva SA, Lima JSS and Alves Al, Estudo espacial do rendimento de grãos e porcentagem de casca de duas variedades de Coffea arabica L. visando a produção de café de qualidade. Biosci J 26:558-565 (2010).

6 Goulet E and Morlat R, The use of surveys among wine growers in vineyards of the middle Loire Valley (France), in relation to terroir studies. Land Use Policy 28:770-782 (2011).

7 Cadot Y, Caillé S, Thiollet-Scholtus M, Samson A, Barbeau G and Cheynier V, Characterisation of typicality for wines related to terroir by conceptual and by perceptual representations: an application to red wines from the Loire Valley. Food Qual Pref 24:48-58 (2012).

8 Morlat R, Terroirs Viticoles: Étude et Valorisation. Oeno Plurimédia, Chaintré, France (2001).

9 Vaudour E, The quality of grapes and wine in relation to geography: notions of terroir at various scales. J Wine Res 13:117-141 (2002).

10 Zou JF, Peng ZX, Du HJ, Duan CQ, Reeves MJ and Pan QH, Elemental patterns of wine, grape, and vineyard soil from Chinese wine-producing regions and their association. Am J Enol Viticult 63:1-10 (2012).

11 Rolle L, Siret R, Segade SR, Maury C, Gerbi V and Journjon F, Instrumental texture analysis parameters as markers of table-grape and winegrape quality: a review. Am J Enol Viticult 63:11-28 (2012).

12 Prodolliet J, Coffee quality assurance: current tools and perspective, in 20th International Conference on Coffee Science, 11-15 October 2004, Bangalore, India. Association Scientifique International du Café, Paris, pp. 120-145 (2004).

13 Dicum G and Luttinger N, The Coffee Book: Anatomy of the Industry from Crop to the Last Drop. New York Press, New York (1999).

14 Oberthür T, Läderach P, Posada H, Fisher MJ, Samper LF, Illera J et al., Regional relationships between inherent coffee quality and growing environment for denomination of origin labels in Nariño and Cauca, Colombia. Food Policy 36:783-794 (2011). 
15 Kerry R and Oliver MA, Determining nugget:sill ratios of standardized variograms from aerial photographs to krige sparse soil data. Precis Agric 9:33-56 (2008).

16 Muller TG, Pierce FJ, Schabenberger $O$ and Warncke DD, Map quality for site-specific fertility management. Soil Sci 65:1547-1558 (2001).

17 Brazil Specialty Coffee Association (BSCA), Grading quality coffee. BSCA Protocols (2008).

18 Matheron G, Les Variables Régionalisées et leur Estimation [The Regionalized Variables and their Estimation]. Masson, Paris (1965).

19 Luz MPS, Estudo da Relação de Fatores Climáticos com a Qualidade do Café na Mantiqueira de Minas. UFLA, Lavras, Brazil (2014).

20 DaMatta FM and Ramalho JDC, Impacts of drought and temperature stress on coffee physiology and production: a review. Braz J Plant Physiol 18:55-81 (2006).

21 Avelino J, Barboza B, Araya JC, Fonseca C, Davrieux F, Guyot B et al., Effects of slope exposure, altitude and yield on coffee quality in two altitude terroirs of Costa Rica, Orosi and Santa María de Dota. J Sci Food Agric 85:1869-1876 (2005).

22 Barbosa JN, Borem FM, Cirillo MA, Malta MR, Alvarenga AA and Alves HMR, Coffee quality and its interactions with environmental factors in Minas Gerais, Brazil. J Agric Sci 4:181-190 (2012).

23 De Assis CP, González-Pérez JA, De La Rosa JM, Jucksch I, Mendonça ES and González-Vila FJ, Analytical pyrolysis of humic substances from a Latosol (Typic Hapludox) under different land uses in Minas Gerais, Brazil. J Anal Appl Pyrol 93:120-128 (2012).

24 Silva PA, Rabelo VM, Calixto JMR, Coelho PO and Gorski IRC, Quality assessment of coffee grown in Campos Gerais, Minas Gerais State, Brazil. Acta Sci Technol 36:739-744 (2014).

25 Silva SA, Terroirs de Café em Lavouras no Município de Araponga-MG. Doctoral thesis, Universidade Federal de Viçosa (2012).
26 Somkuwar RG, Samarth R, Satisha J, Ramteke SD and Sharma AK, Effect of sun exposure on berry development and biochemical constituent in Tas-A-Ganesh grapes grafted on Dog Ridge rootstock. Prog Hortic 47:77-81 (2015).

27 Nascimento MN, Alves JD, Soares AM, Castro EM, Magalhães MM, Alvarenga AA et al., Alterações bioquímicas de plantas e morfológicas de gemas de cafeeiro associadas a eventos do florescimento em resposta a elementos meteorológicos. Ciênc Rural 38:1300-1307 (2008).

28 DaMatta FM, Ecophysiological constraints on the production of shaded and unshaded coffee: a review. Field Crop Res 86:99-114 (2004).

29 Alpizar E and Bertrand B, Incidence of elevation on chemical composition and beverage quality of coffee in Central America, in 20th International Conference on Coffee Science, 11-15 October 2004, Bangalore, India. Association Scientifique International du Café, Paris (2004).

30 Decazy F, Avelino J, Guyot B, Perriot JJ, Pineda C and Cilas C, Quality of different Honduran coffee in relation to several environments. J Food Sci 68:2356-2361 (2003).

31 Laviola BG, Martinez HEP, Salomão LCC, Cruz CD, Mendonça SM and Neto AP, Alocação de fotoassimilados em folhas e frutos de cafeeiro cultivado em duas altitudes. Pesqui Agropecu Bras 42:1521-1530 (2007).

32 Zsófi Z, Tóth E, Rusjan D and Bálo B, Terroir aspects of grape quality in a cool climate wine region: relationship between water deficit, vegetative growth and berry sugar concentration. Sci Hortic 127:494-499 (2011).

33 Carey VA, Saayman D, Archer E, Barbeau G and Wallace M, Viticultural terroirs in Stellenbosch, South Africa. I. The identification of natural terroir units. J Int Sci Vigne Vin 42:169-183 (2008). 